\title{
Liquefaction maps in Babol City, Iran through probabilistic and deterministic approaches
}

\author{
Mehran Naghizadehrokni ${ }^{1,3^{*}} \mathbb{D}$, Asskar Janalizadeh Choobbasti ${ }^{2}$ and Mohsen Naghizadehrokni ${ }^{3}$
}

\begin{abstract}
Background: During an earthquake, significant damage can result due to instability of the soil in the area affected by internal seismic waves. Liquefaction is known as one of the major causes of ground failure due to the earthquake. Various procedures have been classified for assessing liquefaction phenomenon into two main groups, including the deterministic and probabilistic approaches.

Results: Four deterministic methods and one probabilistic approach, which is a reliability procedure are considered for assessing the liquefaction potential in Babol City. The main purpose of this comprehensive research is to evaluate the liquefaction potential and to determine the validation and accuracy of the reliability approach. For this purpose, 60 boreholes including almost 600 field records in different parts of Babol City are analyzed and liquefaction and nonliquefaction areas are identified. Microzonation maps are provided by result analysis of the deterministic and probabilistic procedures. Finally, a 2D borderline, including (CSR) and ( $\left.N_{\text {spt }}\right)$ is obtained by analyzing all data.

Conclusions: The present study illustrates that the evaluation of liquefaction potential by using reliability approach is accurate and this procedure can be recognized as one of the best methods for assessing liquefaction. The map obtained utilizing a reliability approach and the borderline provided in this study, can be utilized for recognizing liquefaction and non-liquefaction areas based on different safety factor and probabilistic procedures.
\end{abstract}

Keywords: Liquefaction, Probabilistic, Deterministic approaches, Microzonation

\section{Background}

Loose sand and silt that is saturated with water can behave like a liquid when shaken by an earthquake. (Seed and Idriss 1971). Soil liquefaction describes a phenomenon whereby a saturated or partially saturated soil substantially loses strength and stiffness in response to an applied stress, usually earthquake shaking or other sudden change in stress condition, causing it to behave like a liquid. (Kutanaei and Choobbasti 2015). On the basis of both the field and laboratory types of soil behavior observations, attempts are made to identifying the best methods for evaluating the liquefaction potential of a particular soil. In the literature, several simplified methods can be found, which are useful in assessing the nonlinear liquefaction potential of soil (Zhang and Goh 2016). Various procedures, known

\footnotetext{
* Correspondence: Naghizadehrokni@geotechnik.rwth-aachen.de ${ }^{1}$ Geotechnical Engineering, RWTH Aachen University, Aachen, Germany

${ }^{3}$ Geotechnical Engineering, IAU Zanjan branch, Zanjan, Iran

Full list of author information is available at the end of the article
}

as conventional methods, have been developed by utilizing case studies and undisturbed soil samples (Rokni et al. 2017; Youd et al. 2001).

An important aspect of geotechnical engineering is the estimation of liquefaction. There are several approaches for determining of soil liquefaction. The cost of collecting high quality undisturbed samples is considerably high and the laboratory conditions cannot simulate the actual conditions of the field; therefore, methods based on in-situ tests, such as the Standard Penetration Test (SPT), the Cone Penetration Test (CPT) and the Shear-wave Velocity Test (Vs), are applied by geotechnical engineers to estimate the soil liquefaction. Civil engineers usually make use of a factor of safety (FS) to evaluate the safety of a structure (Bolton Seed et al. 1985; Youd et al. 2001).

The safety factor is defined as the strength of a member divided by the load applied to it. It is the requirement of most designed codes that the calculated safety factor of a member should be greater than a specified safety factor, a 
value at least larger than one, in order to ensure the safety of the designed structure. Since the specified safety factor is largely determined by experience; hence, there is no rational way of determining such a factor. Since the safety factorbased design method does not account for the variability of the member strength or the applied loading, the probability of failing structures cannot be known. Simplified procedures, originally proposed by Seed (Seed and Idriss 1971), which involved the standard penetration test (SPT) (Toshio Iwasaki 1986), are frequently used in evaluating the liquefaction potential of soils. There are several revisions and updates of the procedures because of its original development. The liquefaction of soil is predicted to occur by using a deterministic method if the factor of safety (FS), which is the ratio of the cyclic resistance ratio (CRR) over cyclic stress ratio (CSR), is less than or equal to one. No soil liquefaction is predicted if (FS) $>1$. In the proposed method, a compilation of methods based on outdoor and laboratory tests are used for liquefaction potential (Rokni et al. 2017; Choobbasti (2015)).

Reliability calculations provide a means of evaluation by combining the effects of uncertainties and provide a logical framework for choosing appropriate factors of safety for the degree of uncertainty and the consequences of failure (Ishihara 1993; Choobbasti (2015)). Thus, a reliability assessment of liquefaction potential seems to be useful in making better engineering decisions. Recently, Hwang (Hwang and Yang 2001) has been conducted an analysis which quantified uncertainties in the (CSR) and (CRR). In this analysis, the uncertainties in the (CSR) and (CRR) are represented in terms of corresponding probability density functions. The probability density function (PDF) of (CSR) is obtained based on a first order second moment (FOSM) (Chameau and Clough 1983) method while the (PDF) of (CRR) is obtained from the first derivative of the (CRR) function, based on a logistic regression analysis of data regarding earthquakes which occurred in the past. However, the (PDF) of (CRR) did not account for the uncertainty in (SPT) resistance. Thus, it is necessary to use a (PDF) of (CRR) which accounts for uncertainties in (SPT) resistance, in order to quantify its effects on liquefaction reliability. Since a variety of approaches provide diverse results geotechnical data in this study are analyzed using 4 deterministic and one probabilistic methods, in order to assess the liquefaction potential in Babol and the results are presented by liquefaction microzonation map and compared. The main purpose of this study is to assess liquefaction potential and provide some guidelines for liquefaction and no-liquefaction areas of Babol City by different methods and finding the best procedure for assessing liquefaction potential. The final aim is providing a 2-D board line based on (CSR) and $\left(N_{s p t}\right)$ parameters for recognizing the liquefaction and mon-liquefaction areas.

\section{Study area and geotechnical investigation}

The structural of earth, especially the tectonic style, of Iran was highly influenced by the development and history of the Tethyan region. The tectonic events, which occurred around the Iranian Plate margins were related to the rifting processes of Gondwana and the subsequent collision with the Arabian plate from the westsouthwest. Fault areas were adjacent the Alborz and Kopeh-Dagh regions to the north, the Makran and Zagros ranges to the west and south, and the east Iran ranges, which border this terrain to the east (Farrokhzad et al. 2012).

Babol, a city of Mazandaran province in the northern part of Iran, is considered as the study area in this research. The city is located approximately $20 \mathrm{~km}$ south of the Caspian Sea on the west bank of the river Babolrood and receives abundant annual rainfall. The collected information used in this research includes more than 60 boreholes drilled in the study area. Due to the large number of boreholes and the considerable changes in the soil layers observed during reviewing and studying the geological structure, an area of $40 \mathrm{~km}^{2}$ that has the highest density of data and similarity in the geological structure is selected at Babol. The raw data taken from the 60 boreholes in the selected ranges are used in this study, ranging from 2 to $20 \mathrm{~m}$ depths and their distribution is shown in Fig. 1.

Liquefaction is developed in loose sandy soils in saturated condition. Almost all area of Babol city have loose sandy soils and in saturated condition, because of Babolroud River. Hence to confront the effects of liquefaction in Babol, recognition of liquefiable regions is very requisite (Farrokhzad et al. 2012).

\section{Methodology of deterministic approaches}

First, approximately 600 SPT records were analyzed using the Seed Method to assess the liquefaction potential in Babol. The first step in Seed procedure was calculating the cyclic stress ratio (CSR) at different depths using the suggested formula.

$$
(C S R)_{M=7.5}=0.65\left(\frac{A_{\max }}{g}\right)\left(\frac{\sigma_{v}}{\sigma_{v}^{\prime}}\right)\left(\frac{r_{d}}{M S F}\right)
$$

In this study, $\left(\sigma_{v}\right)$ and $\left(\sigma_{v}^{\prime}\right) \sigma v$ are the totalov' and effective vertical stress, respectively, and are calculated at different depths. $\left(A_{\max }\right)$ amax is the peak horizontal ground surface acceleration, which is $0.3 \mathrm{~g}$ for Babol, this amount is achieved based on Iranian seismic design code (2800 standard) for Babol City (No 2005), (g) is gravity which is equal to 9.81 and $\left(r_{d}\right)$ is the stress reduction factor obtained for each depth (Idriss and Boulanger 2006; Yaghmaei-Sabegh and MohammadAlizadeh 2012). 


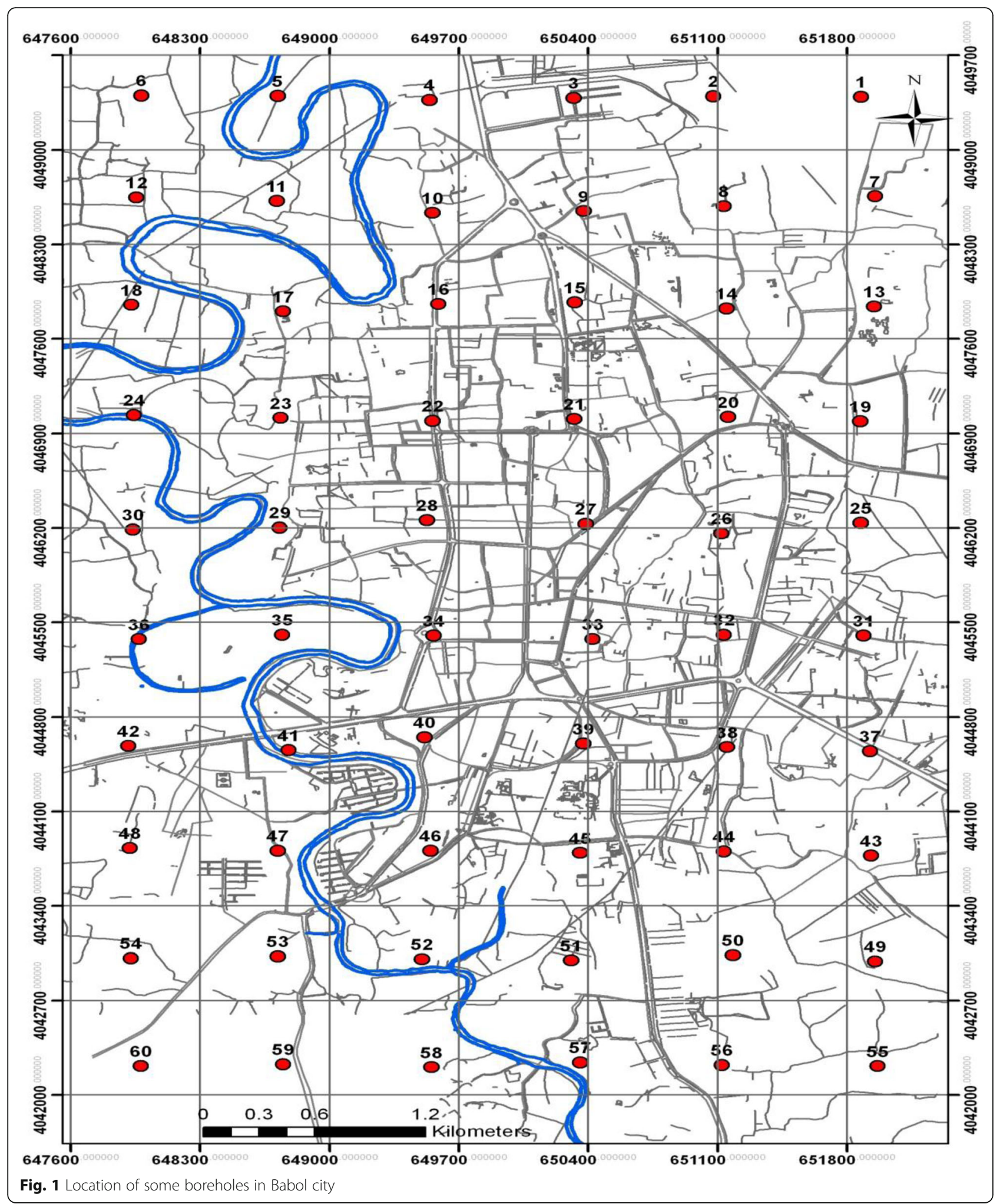

The values of CSR calculated using Eq. (1) pertain to the equivalent uniform shear stress induced by the earthquake ground motions generated by an earthquake having a moment magnitude M. It has been customary to adjust the values of CSR calculated by Eq. (1) so that the adjusted values of CSR would pertain to the equivalent uniform shear stress induced by the earthquake ground motions generated by an earthquake having a 
moment magnitude $\mathrm{M}=7.5$, i.e., $\mathrm{CSR}_{7.5}$ (Idriss and Boulanger 2006).

Thereafter, the cyclic resistance ratio (CRR), which is the capacity of soil to resist liquefaction is obtained using the corrected blow count $\left(N_{1}\right)_{60}$ taken in the laboratory for each bore log. CRR is calculated for soils using $\left(N_{1}\right)_{60}<30$ as:

$$
\text { CRR7.5 }=\frac{1}{34-\left(N_{1}\right)_{60}}+\frac{\left(N_{1}\right)_{60}}{135}+\frac{50}{\left[10\left(N_{1}\right)_{60}+45\right]^{2}}-\frac{1}{200}
$$

In this formula, it is assumed that the soil had acceptable density and is not prone to liquefaction. At $\left(N_{1}\right)_{60}>$ 30 , soils are categorized as non-liquefiable (Cetin and Seed 2004). The soil is relatively fine-grained; thus, the impact of the fines should be considered in Eq. (2) and $\left(N_{1}\right)_{60}$ should be changed to an equivalent clean sand value $\left(N_{1}\right)_{60 c s}$ (Liao and Whitman 1986).

$$
\left(N_{1}\right)_{60 C S}=a+b\left(N_{1}\right)_{60}
$$

The factor of safety versus liquefaction is obtained for each record. The liquefaction and non-liquefaction regions are divided into an area where liquefaction is predicted to occur $(\mathrm{FS}<1)$ and no liquefaction is predicted to occur (FS > 1) (Cetin et al. 2004).

All SPT records are analyzed using the method based on the Technical Specifications of the Highway Japan to recognize liquefiable and non-liquefiable segments, as well. There are some similarities between this method and the Seed Approach, in terms of assessing liquefaction potential. The safety of a factor must be calculated for both procedures. A combination of outdoor test methods is used to estimate the potential of liquefaction. The first step is to survey the following vital criteria for evaluating liquefaction potential in Babol: water table $\leq 10 \mathrm{~m}$, depth of layer susceptible to liquefaction $\leq 20 \mathrm{~m}$, and diameter of gravel soil at $\left(D_{50}\right)>2 \mathrm{~mm},\left(D_{50}\right)<10 \mathrm{~mm}$, and $\left(D_{10}\right)<1 \mathrm{~mm}$ (Adalier and Elgamal 2004).

The next stage of assessing the liquefaction potential involve calculation of (CSR) as expressed in the Seed method. The liquefaction resistance (RL) is then calculated as proposed by the following formula (Bolton Seed et al. 1985) and (RL) is obtained at different depths.

$$
R L=\left\{\begin{array}{lr}
0.0882 \sqrt{\frac{N_{a}}{1.7}} & N_{a}>14 \\
0.0882 \sqrt{\frac{N_{a}}{1.7}} \times 1.6 \times 10^{-6}\left(N_{a}-14\right)^{4.5} & N_{a}>14
\end{array}\right.
$$

The safety of factor is calculated at different depths and the soil is analyzed to identify the liquefiable and non-liquefiable areas.

All SPT records are then analyzed to identify areas of liquefaction and non-liquefaction based on Japanese Standards, Overseas Coastal Area Development Institute of
Japan (OCDI). Unlike previous approaches, the main criterion of this method is the possibility of liquefaction and a definitive amount cannot be calculated (Bolton Seed et al. 1985). Through this method $\left(N_{65}\right)$ which is the equivalent standard penetration test should be calculated using the proposed equation, to predict liquefaction for records in Babol.

$$
N_{65}=\frac{N-0.019\left(\sigma_{v^{\prime}}-65\right)}{0.0041\left(\sigma_{v}^{\prime}-65\right)+1.0}
$$

In this equation, $\left(N_{65}\right)$ is the equivalent $\mathrm{N}$-value, $(\mathrm{N})$ is the $\mathrm{N}$-value of the subsoil, and $\left(\sigma_{v^{\prime}}\right)$ is the effective overburden pressure of the subsoil $\left(\mathrm{kN} / \mathrm{m}^{2}\right)$ calculated in the approach at different depths. In the following step, the equivalent acceleration is calculated by using Eq. (6).

The equivalent $\mathrm{N}$-value refers to the $\mathrm{N}$-value corrected for the effective overburden pressure of $65 \mathrm{KN} / \mathrm{m}^{2}$. This conversion reflects the practice that liquefaction prediction is previously made on the basis of the $\mathrm{N}$-value of a soil layer near a groundwater surface.

$$
A_{e q}=0.7 \frac{\tau_{\max }}{\sigma_{v}^{\prime}} g
$$

The equivalent acceleration should be calculated using Eq. (6) where $\left(\tau_{\max }\right)$ is the maximum shear stress $(\mathrm{kN} /$ $\mathrm{m}^{2}$ ) and $\mathrm{g}$ is the gravitational acceleration. The soil layer should be classified according to the ranges labeled I IV in Fig. 2, using the equivalent $\mathrm{N}$-value and the equivalent acceleration of the soil layer.

Correction $\mathrm{N}$-values and predictions should be done when the fraction of fines content is relatively large. When the fines content (grain size is $75 \mathrm{~mm}$ or less) is $5 \%$ or greater, the equivalent $\mathrm{N}$-value should be corrected before applying in Fig. 2 Corrections of the equivalent $\mathrm{N}$-value are divided into the following three cases.

Case 1: when the plasticity index is less than 10 or cannot be determined, or when the fines content is less than 15\%.

The equivalent $\mathrm{N}$-value (after correction) should be set as $(N)_{65} / C n$. The compensation factor $\mathrm{Cn}$ is given in Fig. 3 The equivalent $\mathrm{N}$-value (after correction) and the equivalent acceleration are used to determine the range in Fig. 2.

Case 2: when the plasticity index is greater than 10 but less than 20 , and the fines content is $15 \%$ or higher, the equivalent $\mathrm{N}$-value (after correction) should be set as both $\left(\mathrm{N}_{65}\right) / 0.5$, and $\mathrm{N}+\Delta \mathrm{N}$, and the range should be determined according to the following situations, where the value for $\Delta \mathrm{N}$ is given by the following equation:

$$
\Delta N_{60}=8+0.45\left(I_{p}-10\right)
$$

1) When $N+\Delta N$ falls within the range $I$, use range $I$.

2) When $N+\Delta N$ fall within the range II, uses range II. 


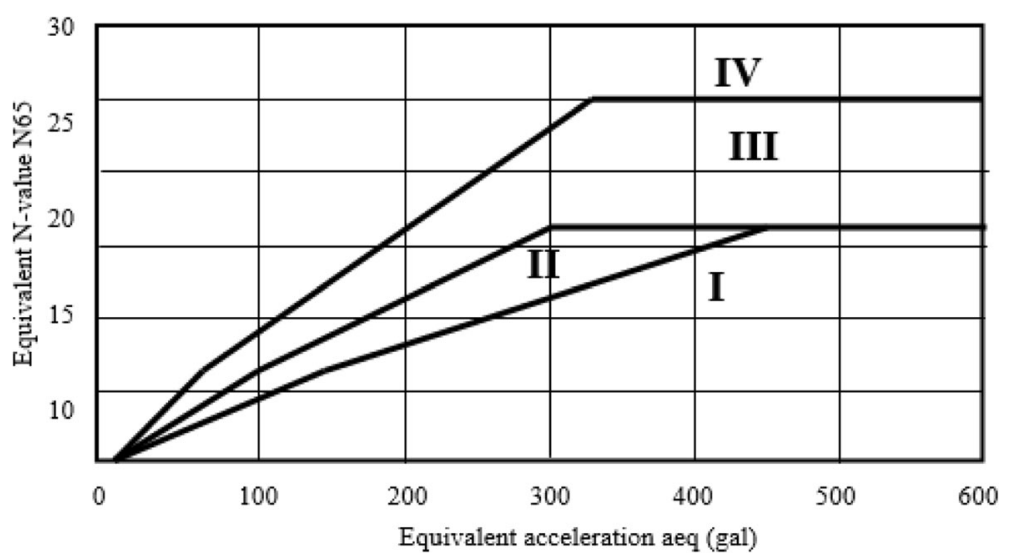

Fig. 2 Classification of soil layer with equivalent $\mathrm{N}$-value and equivalent acceleration

3) When $\mathrm{N}+\Delta \mathrm{N}$ falls within the range III or IV and $\left(N_{65}\right) / 0.5$ is within range I, II or III, use range III.

4) When $\mathrm{N}+\Delta \mathrm{N}$ falls within range III or IV and $\left(N_{65}\right)$ / 0.5 is within range IV, use range IV.

Here, the range III is used for the case 3 , even when the equivalent $\mathrm{N}$-value (after correction) with $\left(N_{65}\right) / 0.5$ is in the range I or II, because the results from the fines content correction are too conservative. The reason that the range IV is not used for the case 3 , even when range IV is given by a correction $\mathrm{N}+\Delta \mathrm{N}$, is that the reliability of the plasticity index in the equation is low when the value is 10 $\sim 20$. Therefore, judging the subsoil as the range IV "possibility of liquefaction is very low" is considered as risky.

Case 3: when the plasticity index is 20 or greater and the fines content is $15 \%$ or higher.

The equivalent $\mathrm{N}$-value (after correction) should be set as $\mathrm{N}+\Delta \mathrm{N}$. The range should be determined according to the equivalent $\mathrm{N}$-value (after correction) and the equivalent acceleration.

The soil layer is categorized according to a diagram that is divided into four segments (Zhang et al. 2015). Possibility of liquefaction is very high, high, low and very low in sections I, II, III, IV and V, respectively. A total of 50 diagrams are drawn for all bore logs and the liquefaction potential is evaluated based on $\left(A_{\text {eq }}\right)$ and $\left(N_{65}\right)$ for different records.

All records are then analyzed using the Iwasaki method (Iwasaki et al. 1984). (LPI) has already been suggested in order to evaluate liquefaction potential. It can be said that the severity of liquefaction is proportional to:

(1) thickness of the liquefied layer; (2) the proximity of the liquefied layer to the surface; and (3) the amount by which the factor of safety is less than 1.0, where (FS) is the ratio of the soil capacity to resist liquefaction to seismic demand which is imposed by the earthquake.

$$
\begin{gathered}
L P I=\int_{0}^{x} F w(z) d z \\
F=1-F S \rightarrow \text { For } \rightarrow F s \leq 1, \quad F=0 \rightarrow \text { For } F S \geq 1, \quad w(z)=10-0.5 z \\
W(z)=10-0.5 z \text { for } z<20 m, W(z)=0 \text { for } z>20 m
\end{gathered}
$$

The weighting factor, $(\mathrm{w}(\mathrm{z}))$, as suggested by Iwasaki et al. 1984 (Toshio Iwasaki et al. 1984), ranges from one

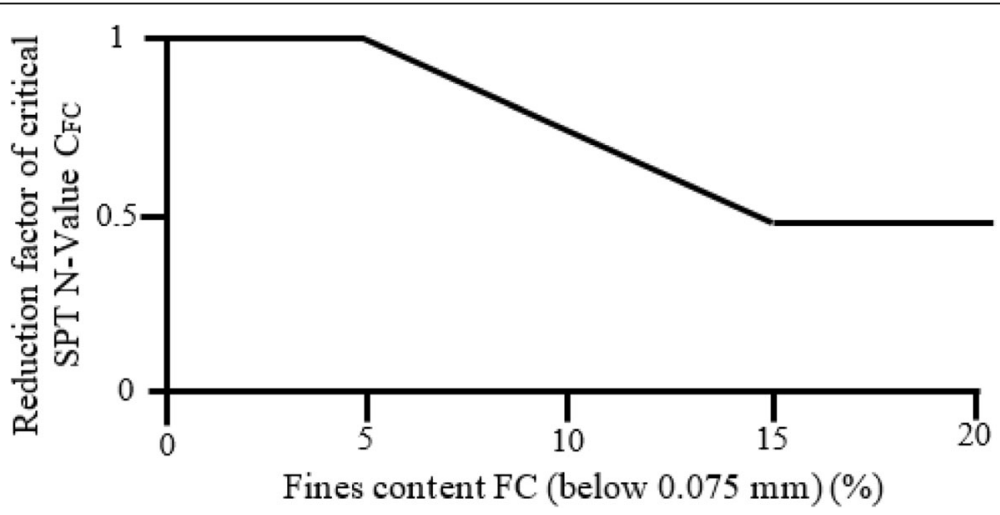

Fig. 3 Compensation factor of equivalent $\mathrm{N}$-value corresponding to fine contents 
at the surface to zero at $20 \mathrm{~m}$ (Toshio Iwasaki 1986). (FS) which is safety factor as defined by Iwasaki (Iwasaki et al. 1981) is straight forward from blow counts from the standard penetration tests (SPT) and median grain size when calculating the liquefaction resistance. (FS) is utilized as defined in the Seed-Idriss simplified procedure. The (LPI) index is calculated at different depths between 0 to $20 \mathrm{~m}$ and the liquefaction and nonliquefaction areas are identified using the index. Iwasaki (T Iwasaki et al. 1981) concluded that severe liquefaction is likely at sites with (LPI) $>15$ and that severe liquefaction is unlikely at sites with $(\mathrm{LPI})<5$. After analyzing all records by this method, it is clear that most areas in Babol can be classified as liquefied sections.

\section{Methodology of reliability probabilistic model}

Performance density function is recognized as one of the major elements in reliability analysis. Some of the uncertainty including errors due to data dispersion around the mean measured and systematic errors in determining the (CRR) and (CSR) are also considered in this method. (R) which is cycle resistance ratio and $(S)$ which is the cycle stress ratio act as random variables which are normally distributed. Therefore, performance function can be defined as:

$$
Z=R-S
$$

If $(Z<0)$ the performance density function is designated as 'failed'. If $(Z>0)$ the performance density function is designated as a safe zone and liquefaction does not occur in that area, and if $(Z=0)$ the performance state is designated as a 'limit state'. The liquefaction probability is defined as the probability that $(Z\langle 0)$. However, an exact evaluation of this probability is not an easy task. Indeed, it is so tough to accurately determine the (PDFs) of random variables such as (R) and (S) (Jha and Suzuki 2009). A simplified calculation approach, the first order and second moment method, have been improved to meet this need. The method utilizes the statistics of the basic independent random variables, such as $(\mathrm{R})$ and $(\mathrm{S})$. If the probability density functions (PDF) and the cumulative distribution function (CPF) of $(\mathrm{Z})$ are defined as $(\mathrm{fz}(\mathrm{Z}))$ and $(\mathrm{Fz}(\mathrm{z}))$, respectively, the liquefaction probability $\left(P_{L}\right)$ then equals the probability of $(Z\langle 0)$ (Sert et al. 2016). If the mean values and standard deviations of $(R)$ and $(S)$ are $\left(\mu_{R}\right)$, $\left(\mu_{S}\right),\left(\sigma_{R}\right),\left(\sigma_{S}\right)$ according to the first order and second moment method, the mean, standard deviation and coefficient of variance of the $(\mathrm{Z})$ function can be obtained by using the following equations.

$$
\delta_{Z}=\frac{\mu_{Z}}{\sigma_{Z}}=\frac{\mu_{R}-\mu_{S}}{\sqrt{\sigma_{R}^{2}+\sigma_{S}^{2}}} \rightarrow \beta=\frac{1}{\delta_{z}}=\frac{\sigma_{Z}}{\mu_{z}}
$$

This index $(\beta)$ is used to calculate the liquefaction probability $\left(\mathrm{P}_{\mathrm{L}}\right)$ which can now be defined as:

$$
P_{L}=\int_{-\infty}^{0} f_{z}(z) d z=\int_{-\infty}^{0} \frac{1}{\sqrt{2 \pi} \sigma_{z}} e^{-\frac{1}{2}\left(\frac{z-\mu_{z}}{\sigma_{z}}\right)^{2}} d z
$$

With new variable $t=\left(Z-\mu_{z}\right) / \sigma_{z}$, one obtains:

$$
P_{L}=\int_{-\infty}^{-\frac{\mu_{z}}{\delta_{z}}} \frac{1}{\sqrt{2 \pi}} e^{\frac{-t^{2}}{2}} d z=\phi\left(-\frac{\mu_{z}}{\delta_{z}}\right)
$$

In the aforementioned equation, $\left(\mathrm{P}_{\mathrm{L}}\right)$ represents failure probability, $\left(\sigma_{z}\right)$ represents the standard deviation, $\left(\mu_{z}\right)$ represents the mean value, $(\beta)$ represents the reliability index and $(\Phi(\beta))$ represents the cumulative probability (Duncan 2000; Juang et al. 2000).

The reliability index $(\beta)$ is defined as the inverse of the coefficient of variation $\left(\delta_{z}\right)$, and is used in calculating the reliability of the results of liquefaction assessment. It is assumed that $(\mathrm{R})$ and $(\mathrm{S})$ are independent variables with a normal distribution to display the process of reliability analysis (Barratt and Day 2016). According to this assumption, the performance function $(Z)$ can be in a normal distribution of $\left(Z_{\sim}\left(\mu_{z}, \delta_{z}^{2}\right)\right)$. By placing the (PDF) of $(Z)$, the following formula is proposed for $(\mathrm{P} L)$ :

$$
P_{L}=\Phi(-\beta)=1-\Phi(\beta)
$$

A computer program is written in MATLAB environment to assess the liquefaction potential based on reliability method for approximately 600 SPT field records in the study area. The seismic information, mean, and coefficient of variation associated with effective parameters are introduced to the program as fixed input parameters to assess liquefaction and parameters relevant to the genetic algorithm (Janalizadechoobbasti et al. 2016).

Genetic algorithm is a numerical search technique which is analogous to the process of natural selection in biology according to Darwin (Dawkins 2016). The evolution of population in nature occurs according to the principles of natural selection and survival of the fittest. Based on these principles, individuals in a population compete with each other. Those who best fit their environment have the most chance of survival and will have relatively more offspring in the next generation. Conversely, individuals with poor performance produce fewer offspring and may even vanish and produce no offspring at all. Hence, characteristics of the most successful individuals in surviving will spread to an increasing part of the population. In summary, GA works with a population of individuals each representing a possible solution (answers) for a given problem (McCully and Bleobaum 1996). The population of individuals evolves through mating between members. Most optimization techniques require derivatives of the problem functions whereas in GA method only information related to each member is of prime importance. While derivation of the functions is not obtained in a straightforward manner in 
many cases, GA methods do not deal with the problem details. Therefore, a GA method is more flexible than any other optimization process especially because of the algorithm benefits form coded and binary variables, which are suitable for computer programming. It should be mentioned that some parameters affect the convergence rate in GA process, for example population size, mutation, and crossing are such parameters. Hence, in order to minimize the effect of these parameters on convergence rate, a sensitivity analysis is usually performed prior to the main GA analysis through which an appropriate range for the variables is introduced. Then, one of the variables is assumed to be the prime variable while the others remain constant. Thereafter, the rate of convergence is observed for that variable over the predefined range. The process is continued for each variable until a suitable range is established for each variable. The sensitivity analysis conducted for minimization of the function of reliability index has led to the following appropriate values to be applied for GA analysis: probability of crossover, $\mathrm{Pc}=0.65$, initial population, $\mathrm{Npop}=50$, mutation probability, $\mathrm{Pm}=0.025$, and maximum number of generation, MaxGen $=40$. Moreover, these parameters are also shown in Table 1, where a very concise description of the GA operations and related parameters is also presented.

The geotechnical information required for assessment of liquefaction involves groundwater level, soil bulk density, depth of soil layers, soil type, (SPT) number, percentage of fines (sieve 200) as variable input parameters. The application reliability index values are calculated from boreholes to different depths based on the flowchart designed and the probability of liquefaction is then evaluated in these depths. Stages of current investigations as well as sequences of GA process are presented in Fig. 4. In this Figure, $\mathrm{X}, \mathrm{m}$ and $\mathrm{C}$ are the vector of the random variable, the mean vector and the matrix covariance, respectively.

\section{Result and discussion}

Evaluating the potential of liquefaction in soil of Babol city in Iran is a very important issue since the soil in some areas are comprised of sand, seismic area, increasing level of underground waters and consequently saturation of soil. In this paper, about 600 SPT data are collected from different labs in Babol city and are analyzed using five approaches, which have previously been described. One borehole log is chosen based on the engineer adjudication and analysis is performed. The reason of selecting this borehole is that we can find the defect of deterministic procedures against probabilistic method. Table 2 illustrates a summary of this deterministic and probabilistic analysis at different depths where soil performance against liquefaction is reported. For each of these cases, the (CSR), (CRR), safety factor with three approaches and the probability of liquefaction $\left(P_{L}\right)$ are calculated continuously at all depths, so that a profile of $\left(P_{L}\right)$ can be drawn. A liquefiable sandy layer existed from a depth of 2 to $22 \mathrm{~m}$ and the water table is at a depth of $1.8 \mathrm{~m}$. The site is analyzed for $\left(A_{\max }\right)=0.3 \mathrm{~g}$, and $(\mathrm{Mw})$ $=7.5$ (based on the regulations of the design of buildings against earthquakes in Iran; classification for high seismic

Table 1 Operation description and related parameter in GA cycle

\begin{tabular}{|c|c|c|c|}
\hline Operation & Description & Related Parameters & Parameter description \\
\hline Population & $\begin{array}{l}\text { GA starts with choice of some individuals (potential } \\
\text { answers for the problem) generated using a random } \\
\text { generator. The set of chosen values are called } \\
\text { population and the first set is referred to as 'initial } \\
\text { population'. Members of the population are chosen to } \\
\text { act as parents to produce children for next generation } \\
\text { (next set of potential answers). }\end{array}$ & Npop & $\begin{array}{l}\text { The size of the population is the number of the } \\
\text { members that constitute the population. It is shown } \\
\text { usually by parameter 'Npop'. The number of initial } \\
\text { population is a matter of concern and is usually } \\
\text { adopted based on the sensitivity analysis. In this study, } \\
\text { it is selected as Npop }=50 \text { after sensitivity analysis. }\end{array}$ \\
\hline Generation & $\begin{array}{l}\text { In each cycle in GA, when the number of the produced } \\
\text { children (new potential answers) is equal to the size of } \\
\text { population(Np), then one generation is formed. }\end{array}$ & MaxGen & $\begin{array}{l}\text { Maximum number of generation 'MaxGen' is a } \\
\text { predefined number which is a criterion that checks the } \\
\text { termination process. When MaxGen is reached, the GA } \\
\text { process is terminated even if the convergence criterion } \\
\text { is not satisfied. }\end{array}$ \\
\hline Crossover & $\begin{array}{l}\text { Operates on two chromosomes and swaps some of } \\
\text { their genes which creates two new chromosomes } \\
\text { representing two new individuals. In GA context, these } \\
\text { new individuals may be considered as new potential } \\
\text { answers. }\end{array}$ & PC & $\begin{array}{l}\text { Crossover operation is carried in a probabilistic manner } \\
\text { and hence a probability number is assigned to it which } \\
\text { is referred to as 'crossover probability' or 'Pc'. Similar to } \\
\text { Npop, sensitivity analysis may be carried to select the } \\
\text { best value for Pc or it may be adopted based on some } \\
\text { other inference. }\end{array}$ \\
\hline Mutation & $\begin{array}{l}\text { This operator occasionally changes the produced } \\
\text { children (new potential answers) based on probabilistic } \\
\text { principles by exchanging some of their genes and } \\
\text { preserves the diversity of the population (set of potential } \\
\text { answers) by introducing new members and also } \\
\text { prevents the local optimums. }\end{array}$ & $\mathrm{Pm}$ & $\begin{array}{l}\text { Mutation occurs probabilistically according to a chosen } \\
\text { rate which, again, may be adopted based on sensitivity } \\
\text { analysis. It implies on the probability for the mutation of } \\
\text { a gene usually indexed by binary numbers ' } 0 \text { ' and ' } 1 \text { ' in } \\
\text { the chromosomes' string. If the total number of handled } \\
\text { genes is assumed to be } n \text {, then } P m \times n \text { genes are mutated. }\end{array}$ \\
\hline
\end{tabular}




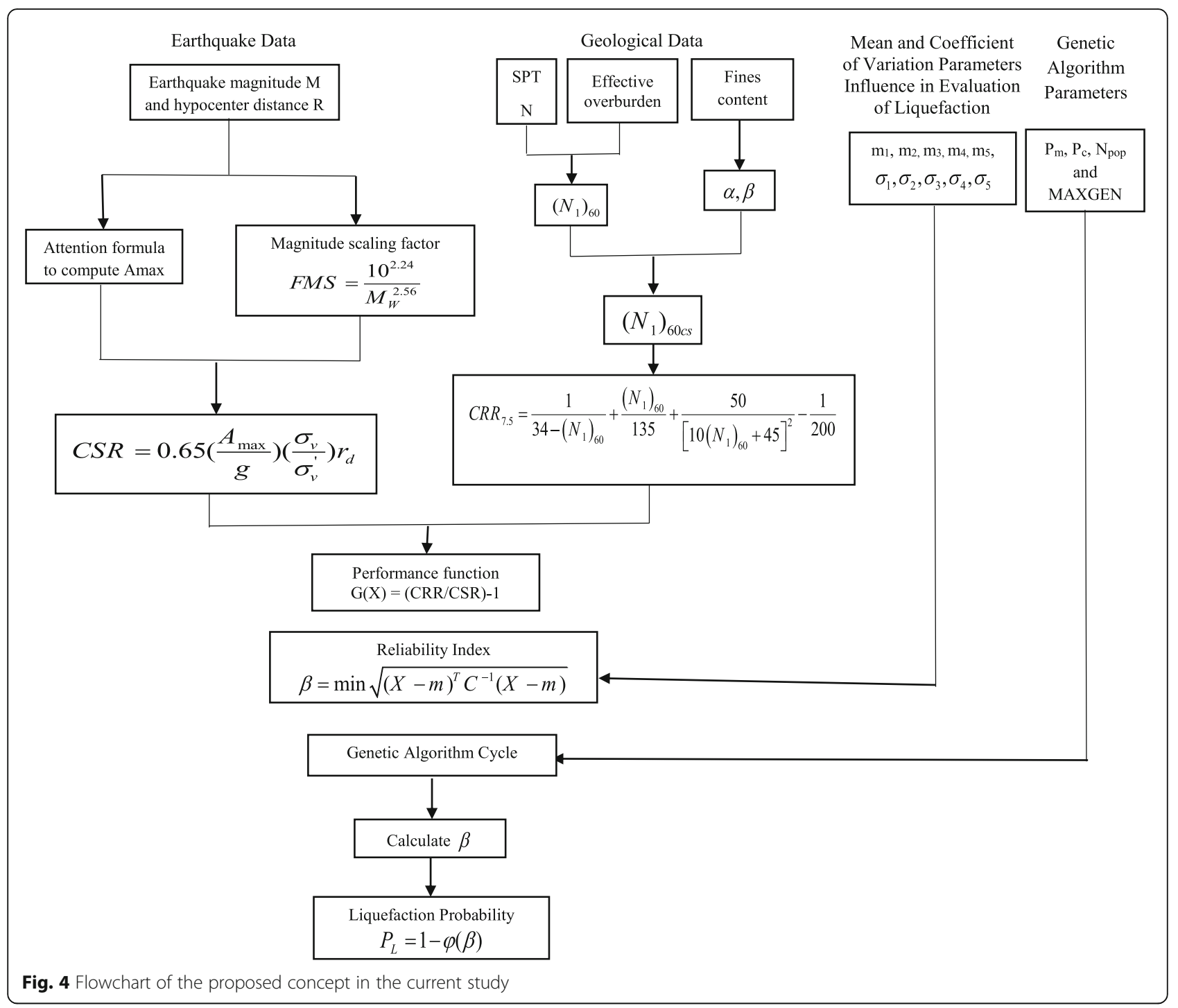

risk) (Yaghmaei-Sabegh and Mohammad-Alizadeh 2012). The soil parameters and the factors of safety against liquefaction, using deterministic procedures and probability of liquefaction $\left(P_{L}\right)$, are shown in Table 1 . The different factors of safety in the range of 0.017 to 1.7 are obtained for the same input parameters. In this table $\left(F_{S 1}\right)$ illustrates the factor of safety related to Seed, $\left(F_{S 2}\right)$ indicates the factor of safety related to the Highway Bridge of Japan and finally $\left(F_{s a}\right)$ shows the different areas related to the OCDI procedures, respectively.

With this profile, it is possible for the engineer to determine which layers are sensitive to liquefaction from the viewpoint of an acceptable risk level. This advantage is also observed in Table 2. For example, in the case of 1 at a depth of $2 \mathrm{~m}$, the comparison of calculated values by Seed et al. and the Highway Bridge of Japan approaches suggest that there would be liquefaction, since $(\mathrm{CRR})>(\mathrm{CSR})$ (albeit slightly). On the other hand, the
OCDI approach shows that the soil is in the 3 area and the possibility of liquefaction is low. However, the field observation indicates the occurrence of liquefaction. The probability of liquefaction for this case is 26.5, which suggests that liquefaction may not be possible. Similar observation is found in the case of 5 but in this case, the reliability approach confirms the result of Seed and Highway Bridge of Japan methods, as it indicates that liquefaction will occur $\left(\mathrm{P}_{\mathrm{L}}=91 \%\right)$. In the case of 7 , the Seed method yields $\left(F_{S 1}\right)=0.58$ and OCDI method shows that the soil is in the second area, which suggests that liquefaction will occur. Moreover, the field observation indicates that the Highway Bridge of Japan method shows the possibility of occurrence of liquefaction. In this case, the result of the probability analysis $\left(P_{L}=52.2\right)$ does not provide a credible support for the occurrence of liquefaction. Figure 5 shows a sample output of the PL profile, along with the $\left(F_{S 1}\right),\left(F_{S 2}\right)$ and $\left(F_{s a}\right)$ profiles, 
Table 2 The typical bore log data in Babol

\begin{tabular}{llllllllllll}
\hline Row & Depth $(\mathrm{m})$ & $\gamma\left(\mathrm{Kg} / \mathrm{m}^{3}\right)$ & $N_{s p t}$ & $F_{c}(\%)$ & $\sigma_{v}\left(\mathrm{kN} / \mathrm{m}^{2}\right)$ & $\sigma_{v}^{\prime}\left(\mathrm{kN} / \mathrm{m}^{2}\right)$ & $F_{s 1}$ & $F_{s 2}$ & $F_{s a}$ & $\beta$ & $P_{L}(\%)$ \\
\hline 1 & 2 & 19.3 & 6 & 78.3 & 38.6 & 19 & 0.46 & 0.026 & 3 & 0.68 & 26.5 \\
2 & 4 & 18.1 & 4 & 78.3 & 72.4 & 33.2 & 0.24 & 0.49 & 3 & -1.4 & 93 \\
3 & 6 & 19.4 & 7 & 100 & 116.4 & 57.6 & 0.33 & 0.017 & 1 & -9.4 & 100 \\
4 & 8 & 19.8 & 10 & 52.5 & 158.4 & 80 & 0.41 & 0.47 & 3 & -1.02 & 84.6 \\
5 & 10 & 18.6 & 12 & 3.1 & 186 & 88 & 0.37 & 0.27 & 4 & -1.34 & 91 \\
6 & 12 & 19.3 & 20 & 4.2 & 231.6 & 114 & 0.59 & 0.34 & 3 & -1.2 & 88.5 \\
7 & 14 & 19.3 & 20 & 4.2 & 270.2 & 133 & 0.58 & 0.34 & 2 & -0.05 & 52.2 \\
8 & 16 & 19.9 & 21 & 100 & 318.4 & 161.6 & 0.79 & 0.92 & 4 & -1.19 & 88.4 \\
9 & 18 & 20.3 & 20 & 100 & 365.4 & 189 & 0.76 & 0.97 & 4 & -0.2 & 60.7 \\
10 & 20 & 20.6 & 22 & 81.9 & 412 & 216 & 0.86 & 1.03 & 4 & 0.89 & 18 \\
11 & 22 & 20.5 & 21 & 100 & 451 & 235.4 & 0.83 & 1.06 & 4 & - & - \\
\hline
\end{tabular}

as well as a comparison between Seed's and High Bridge's output method which are indicated as Figs. 5d, $5 \mathrm{a}, 5 \mathrm{c}, 5 \mathrm{e}$ and $5 \mathrm{~b}$, respectively.

A comparison of the $\left(F_{S 1}\right),\left(F_{S 2}\right)$ profiles, similar to those shown in Fig. 5b, are quite useful as they show which layers are likely to liquefy. However, this assessment of the liquefaction potential is essentially deterministic. As a result of the uncertainties involved in the calculation of (CSR) and (CRR), such a deterministic approach is rather inappropriate. The drawing of the $\left(P_{L}\right)$ profile as shown in Fig. $5 \mathrm{~d}$, offers an alternative on which engineering decisions may be based.

\section{Liquefaction hazard maps}

Liquefaction hazard maps are useful tools for identifying areas with a high likelihood of liquefaction-induced ground deformation. Since the creation of improved gadgets, with the advances in computer technologies, geographic information systems (GIS) are now being used to generate hazard maps. Here, a zone map from Babol city is provided which illustrates the liquefaction and non-liquefaction areas through GIS program. After the collection of all information associated with boreholes, followed by their analysis and determination of the non-liquefaction and liquefaction areas, data are entered in (GIS) and liquefaction and non-liquefaction regions are specified with the help of Kriging Approach which is one of the best methods of interpolation (Journel 1986). In this paper, liquefaction maps are drawn through four deterministic procedures which include: Seed et al., OCDI, Highway Bridge of Japan and Iwasaki procedures, respectively and one probabilistic approach, which is the reliability method.

As it can be seen in the map derived from Highway Method, all sections in the map are recognized as liquefaction and non-liquefaction areas. Almost all southern segments of Babol are identified as non-liquefaction areas by this method. While, center of the city is recognized as liquefaction area and it mean that this section has potential of liquefaction. Concerning the north area, as it can be seen, there are some liquefiable and non-liquefiable areas in the north.

Seed approach gives the same results to Highway method especially in central and northern area in terms of identifying the liquefaction and non-liquefaction segments. It can be concluded that we can achive the same results for assessing liquefaction potential by utilizing both approaches. Whereas, there are some little differences in southern area as there are some liquefiable segments in southern area whereas in previous procedure all southern area of Babol were recognized as liquefaction areas.

In this map which is based on OCDI method it can be argued that some western sections in the center of Babol just has very high potential for liquefaction and the severity of liquefaction has been reduced in other sections. As it can be seen center of the city has high potential for liquefaction and the severity of liquefaction has been reduced during approaching to southern area. Some segments of northern area do not have any potential for liquefaction whereas the above section of northern area, the severity of liquefaction has been increased to low liquefaction potential.

In all maps derived from deterministic methods, the central areas of Babol are known as the liquefaction region, whereas when moving from the center of city to the north, first, some non-liquefaction areas and after that some liquefaction region can be observed. Overall, numerous similarities exist between the central and northern areas in all maps obtained by deterministic procedures, while many discrepancies are seen in the southern part in these maps. In the resulting map of the Highway Bridge of Japan approach which is shown in Fig. 6, almost all southern region is recognized as nonliquefaction areas while in liquefaction areas obtained by Seed method which is indicated in Fig. 7, liquefaction is observed in some parts of the southwest and the 

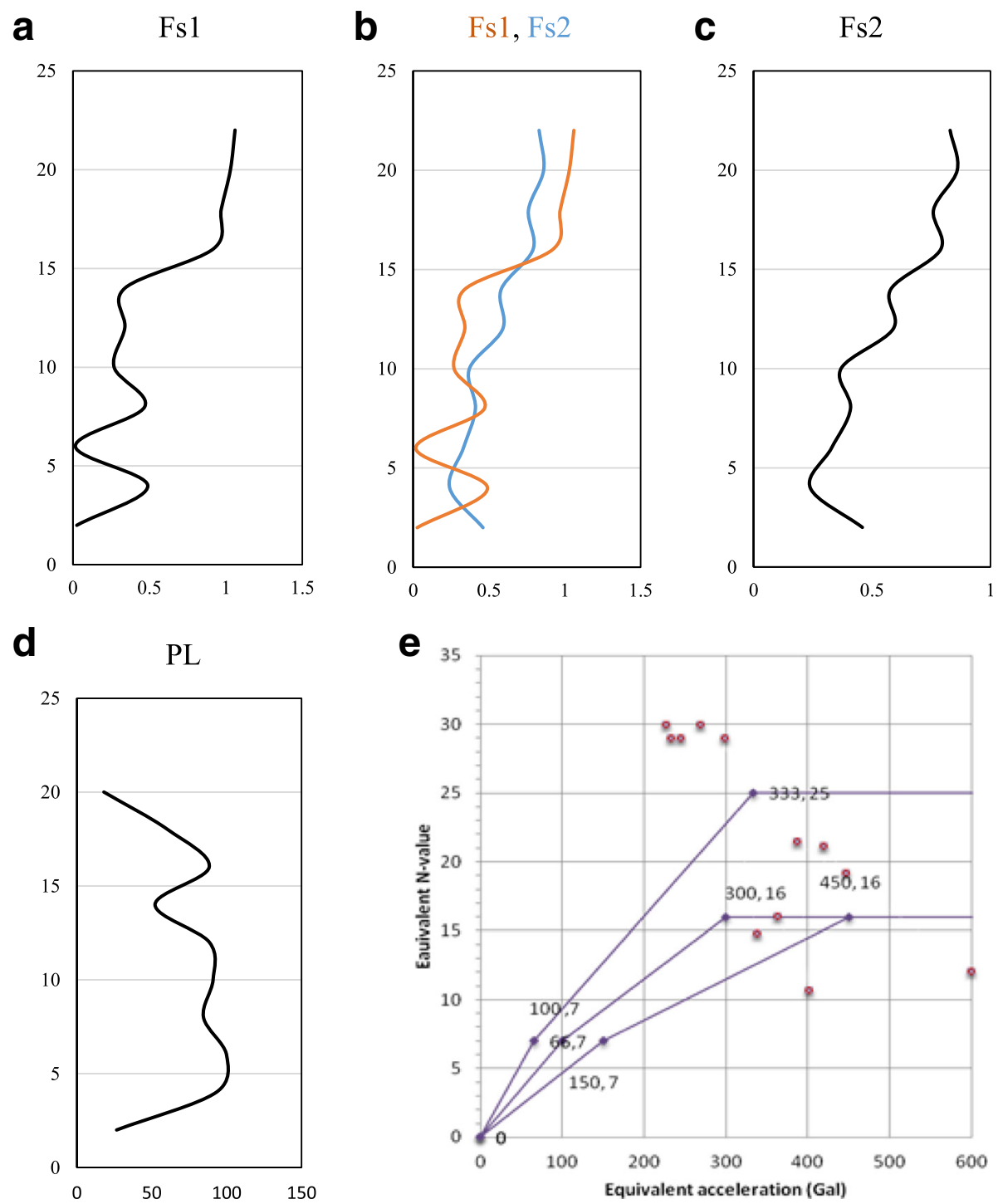

Fig. 5 Liquefaction potential evaluation related to bore log

southern regions of Babol. On the other hand, the analysis of data using the OCDI method which is illustrated in Fig. 8 gives different results. According to the map drawn using the OCDI approach, the severity of liquefaction reduced during approaching to the southern area and liquefaction regions changed to less liquefied segments. In addition, part of the southern west of the city where are far from the river are marked as the region with high intensity liquefaction while in all three previous deterministic procedures (Iwasaki, Seed and Highway Bridge of Japan), this area is known as non-liquefaction segment. The initial impression from the map drawn by Iwasaki method, which can be seen as a Fig. 9, is that in the southern area, high intensity liquefaction is observed whereas this region is recognized as liquefaction region in Seed and Highway
Bridge of Japan approach and is marked as low intensity liquefaction in the OCDI method. Moreover, western region (around the river which is called Babolrod) where is marked as high intensity liquefaction in OCDI method is considered as liquefaction area in Iwasaki procedure.

Concerning the map derived reliability approach in Fig. 10, it can be argued that just some central area is recognized as high liquefaction and southern sections of map illustrate liquefaction and low liquefaction areas, respectively. On the other hand, the severity of liquefaction is reduced from low liquefaction areas to non-liquefaction sections by approaching the northern segments of Babol.

From what is earlier discussed, by comparing maps derived from deterministic and probabilistic approaches, it can be concluded that the map obtained by reliability 


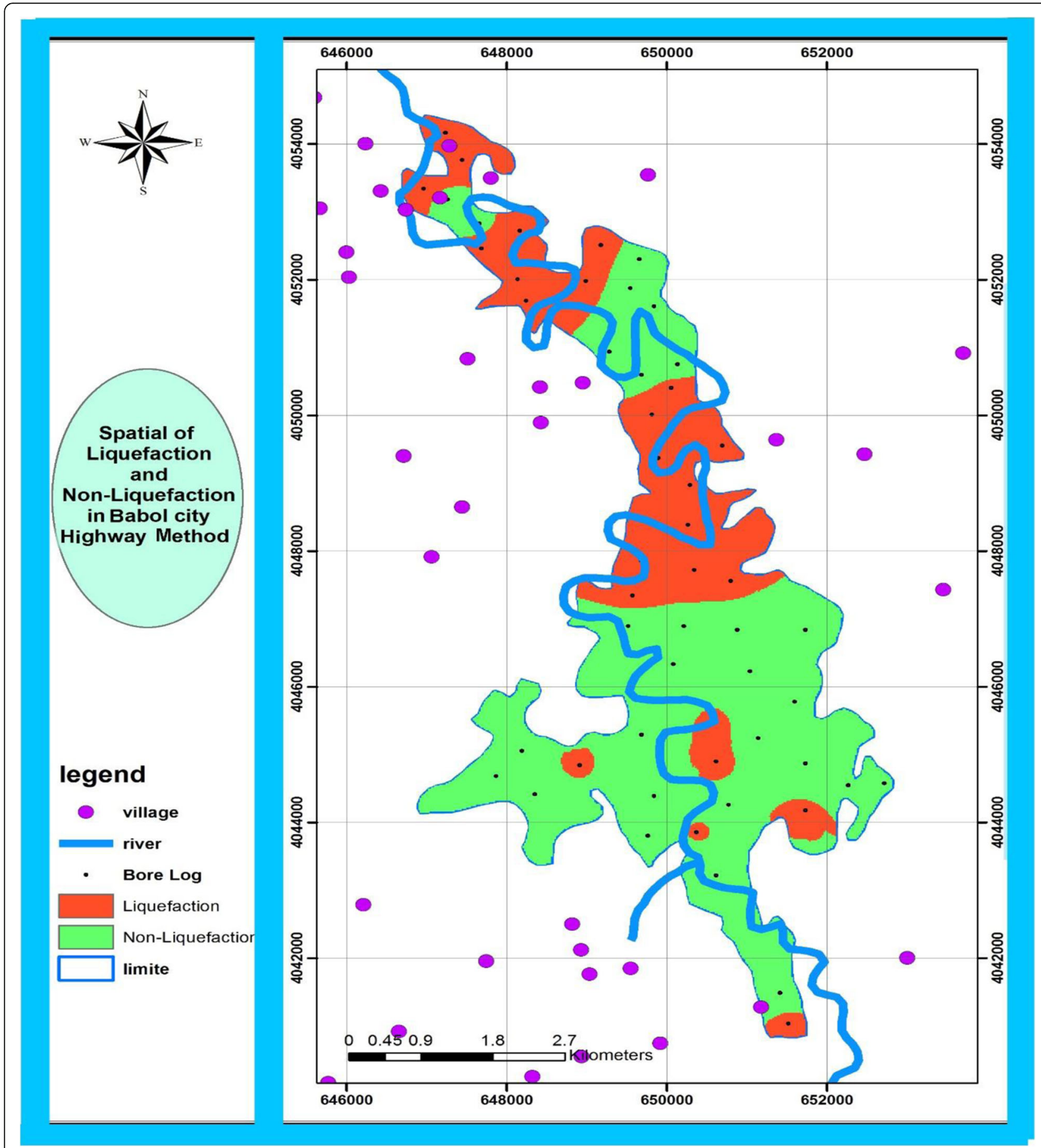

Fig. 6 Liquefaction hazard map of Babol (Highway Bridge of Japan procedure)

method has an acceptable accuracy. The reason for this trust in the reliability procedure is that in the analysis of reliability, the potential of indicators, which is one of the best ways to assess the safety against liquefaction is utilized. Furthermore, this index provides more certain in comparison with deterministic methods and includes details of statistical variables and parameters loading resistance, as well while deterministic approaches are based on measurements in location.

\section{Liquefaction limit state}

In a reliability analysis of soil liquefaction potential, it is necessary to define a limit state which separates liquefaction from non-liquefaction areas. In this paper, 


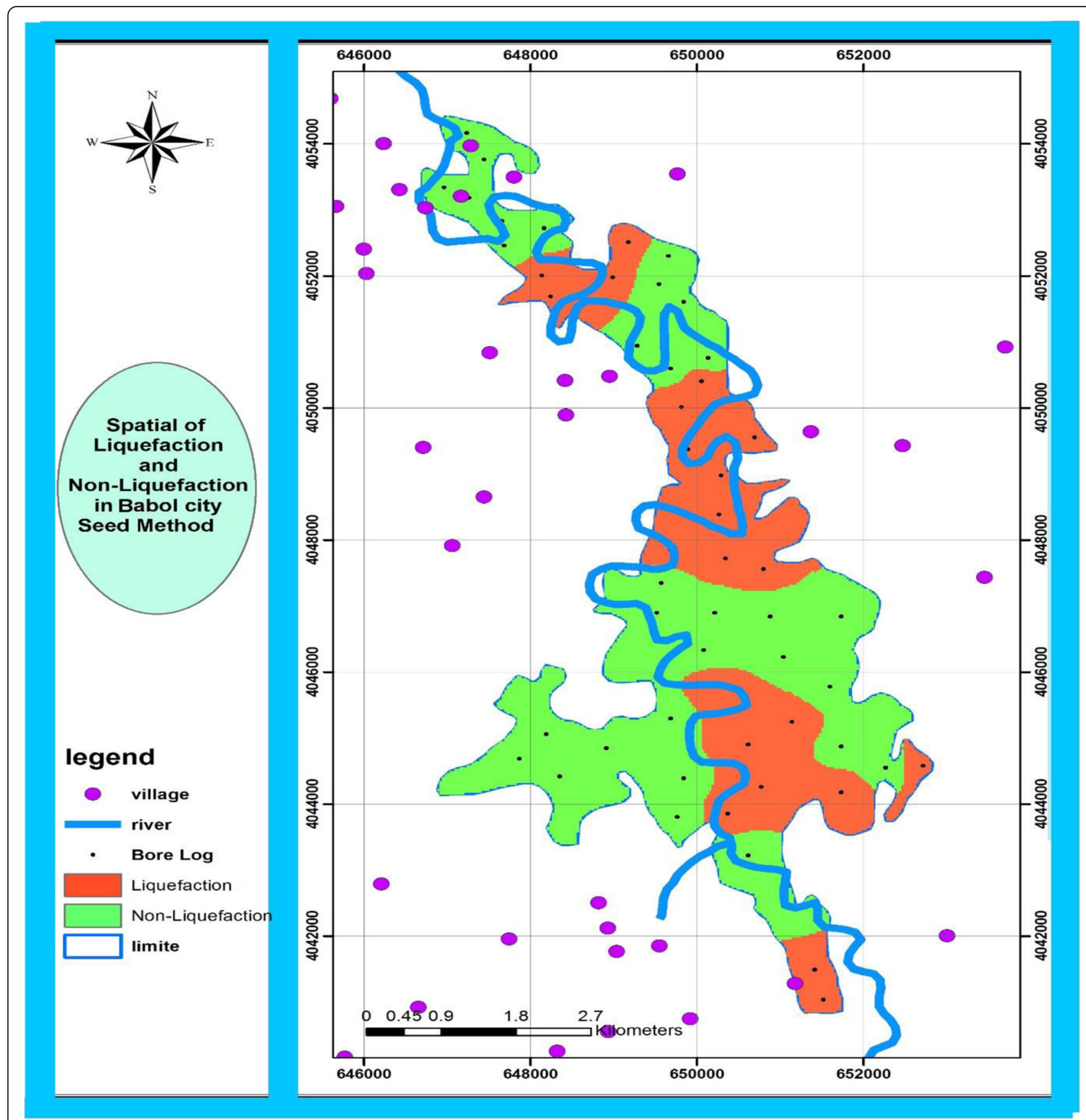

Fig. 7 Liquefaction hazard map of Babol (Seed approach)

the boundary curve in the standard penetration test (SPT)-based simplified method is recommended for the all data which is shown in Fig. 11. First of all, the amount of (CSR) is calculated for each depth and the amount of tension on the modified standard penetration is plotted. A repetition of the process for different depths at different sites resulted in the formation of a set of points from which the modified standard penetration and cycle stress ratio is obtained. In view of the set of ordered pairs, each with specific characteristics (number of (SPT), cycle stress ration and liquefaction condition specified) resulted in the formation of relatively clear border between liquefaction and non-liquefaction points (Fig. 11).

\section{Conclusion}

In this study, liquefaction potential is evaluated in Babol city through four deterministic procedures, including Seed, OCDI, Iwasaki and Highway Bridge of Japan methods, respectively and one probabilistic approach, 


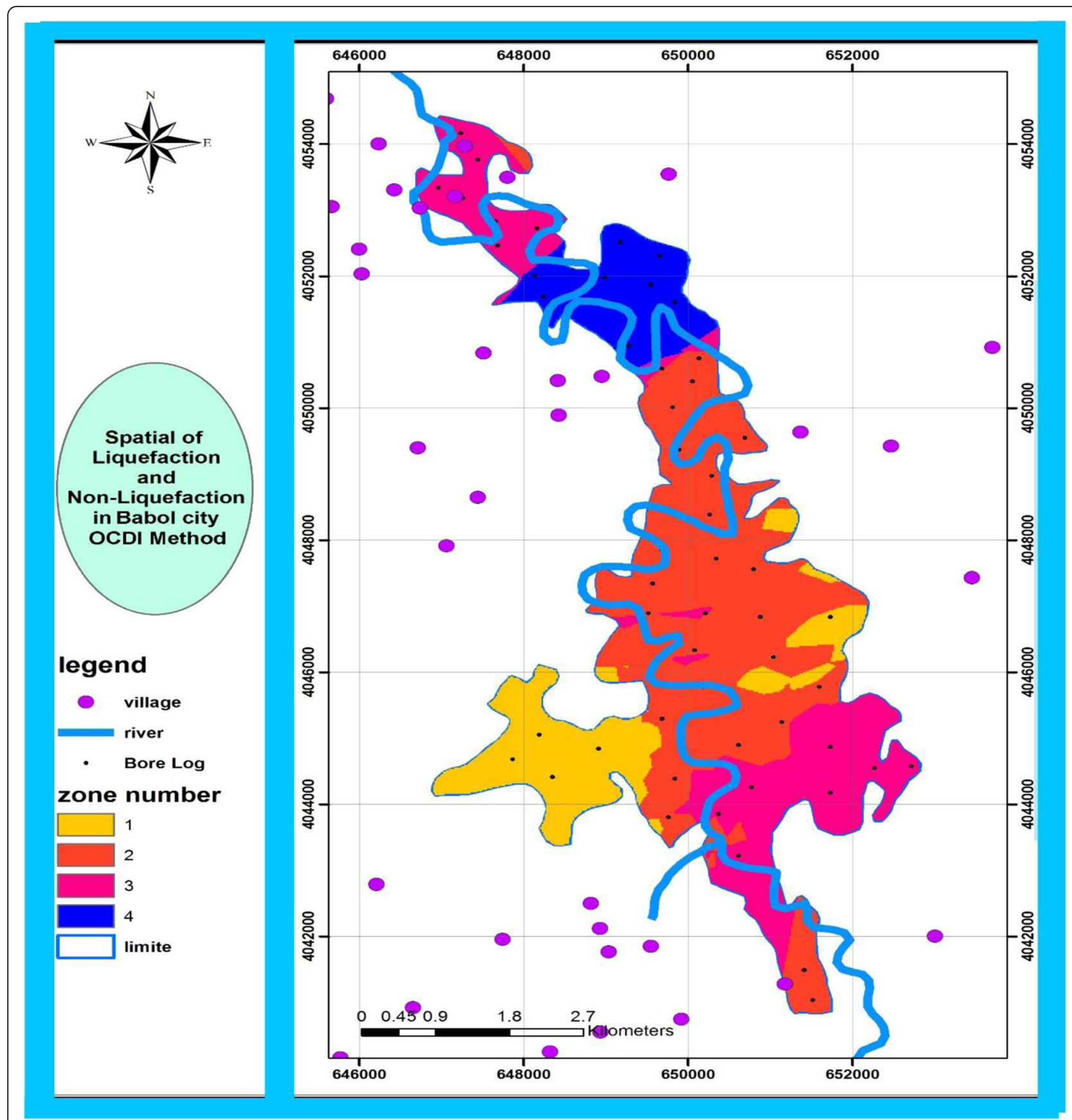

Fig. 8 Liquefaction hazard map of Babol (OCDI approach)

which is the reliability method. Almost 60 boreholes are analyzed in the area of study and liquefied and nonliquefied regions are determined. To better understand the results, analyzed data are presented for microzonation maps. There are almost similar answers in the central and northern areas in all maps derived from deterministic procedures, which can be concluded that central areas of Babol are recognized as liquefaction with high severety; however, considerable discrepancies resulted in the answers in the southern part of Babol and this issue demonstrated the weakness of the deterministic approaches, since similar data are obtained with different results.

After assessing and analyzing all data by reliability method in terms of determining liquefaction and nonliquefaction areas, a borderline in a 2D environment, including (CSR) and $\left(N_{s p t}\right)$ is obtained. Liquefaction assessment can be made through this borderline. The 


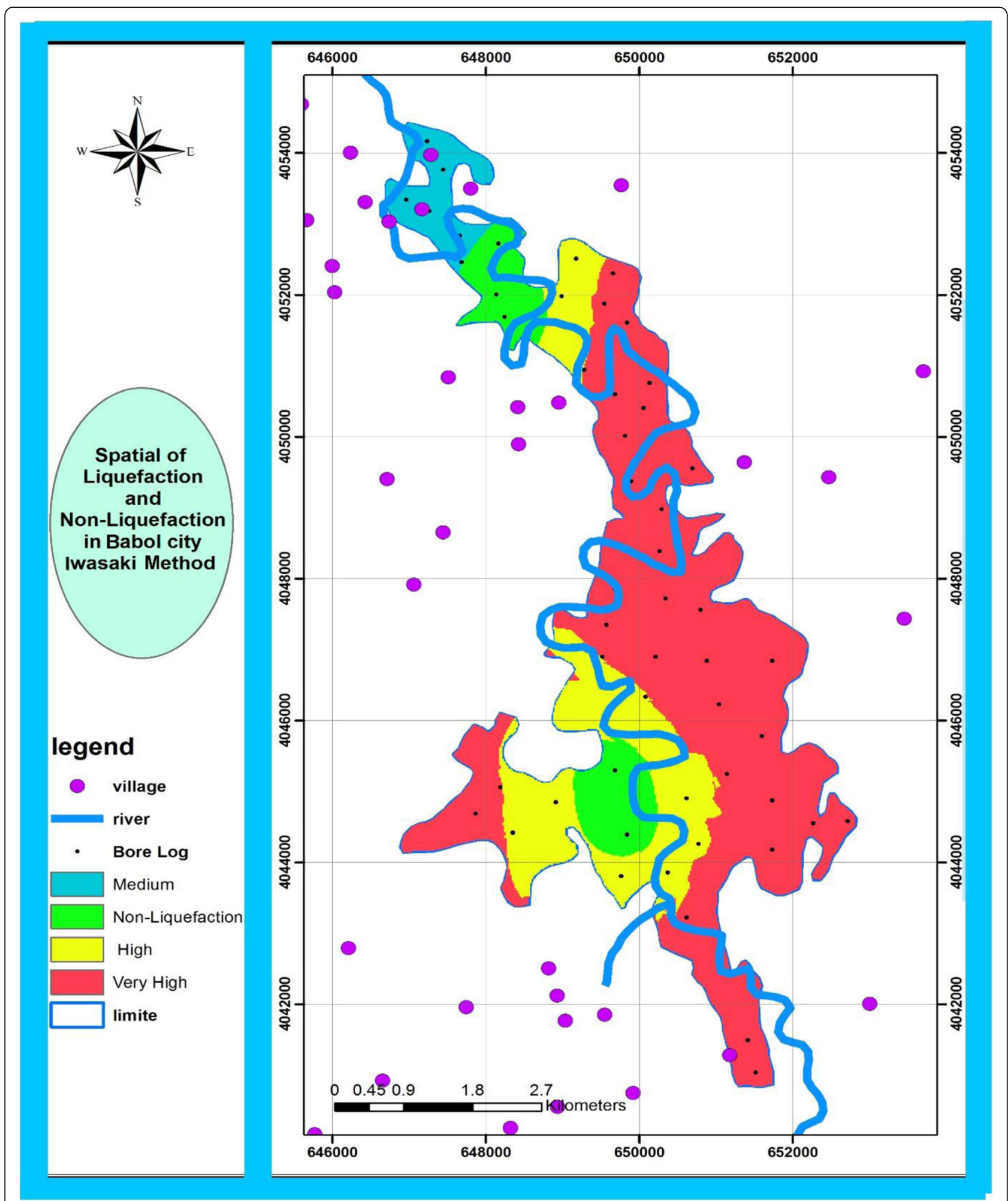

Fig. 9 Liquefaction hazard map of Babol (Iwasaki procedure)

initial impression from the microzonation map which is obtained by probabilistic approach is that almost all areas in Babol, except for the northern part of the city are considered as being liquefied with different intensity. Finally, by comparing the maps obtained for the deterministic and probabilistic methods it is concluded that 


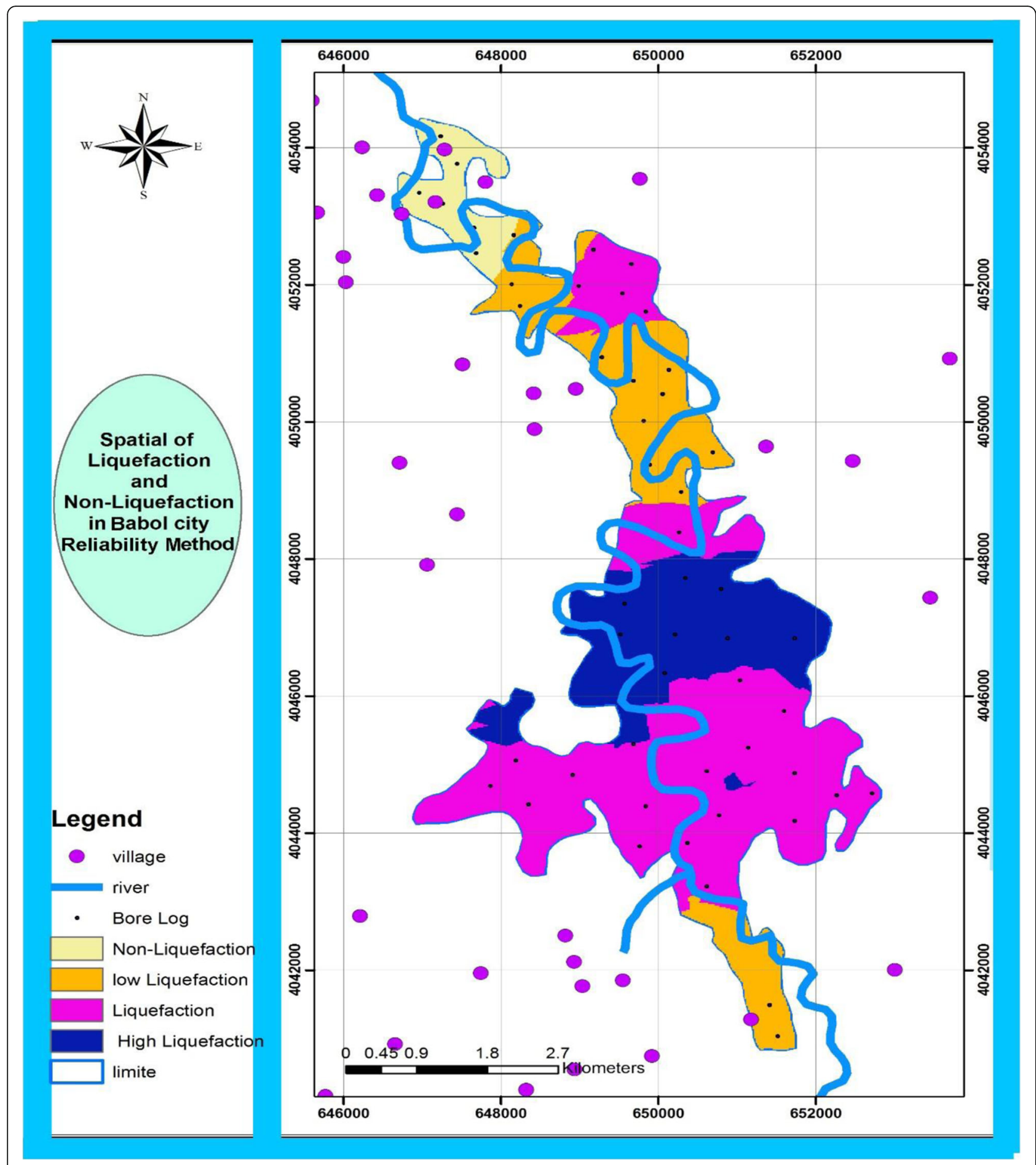

Fig. 10 Liquefaction hazard map of Babol (Reliability method)

the map obtained from a reliability method had the highest accuracy. From all that have been discussed so far, by comparing the maps obtained by deterministic and probabilistic procedures, it is concluded that the map which is obtained from a reliability approach possessed the highest accuracy.
Probabilistic reliability method is considered as the most logical and practical approach for accounting the different uncertainties, including both the model and measurement uncertainties. Therefore, it is recommended that this new approach can be used in discussions of sub-zones since the evaluation of liquefaction by only using deterministic 


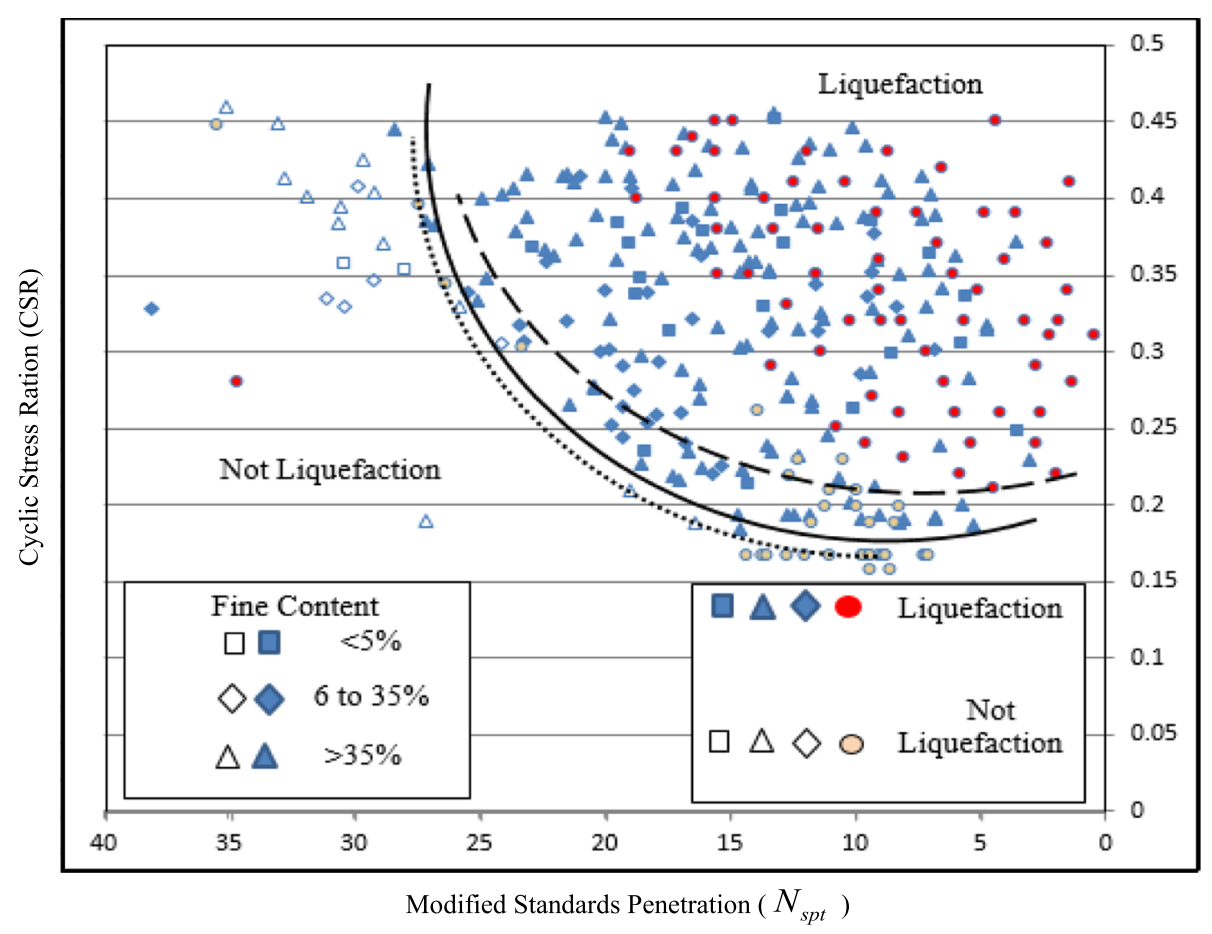

Fig. 11 Limit state (boundary between liquefaction and non-liquefaction states)

methods are insufficient and inaccurate. Overall, it can be stated that the map presented in this study can have numerous applications for the expansion and development of the city of Babol and in comparison with similar researches in this area; it is more accurate due to the leveraging reliability procedure.

\section{Acknowledgements}

We thank Dr. Mobing Afzalirad for some data inputs and comments on the manuscript.

\section{Funding}

This work does not have any funding.

\section{Authors' contributions}

All authors contributed to the database construction and analysis; all read and approved the submitted manuscript.

\section{Competing interests}

The authors declare that they have no competing interests.

\section{Publisher's Note}

Springer Nature remains neutral with regard to jurisdictional claims in published maps and institutional affiliations.

\section{Author details}

${ }^{1}$ Geotechnical Engineering, RWTH Aachen University, Aachen, Germany. ${ }^{2}$ Geotechnical Engineering, Babol Noshirvani University of Technology, Babol, Iran. ${ }^{3}$ Geotechnical Engineering, IAU Zanjan branch, Zanjan, Iran.

Received: 15 October 2017 Accepted: 11 December 2017

Published online: 04 January 2018

\section{References}

Adalier, K., and A. Elgamal. 2004. Mitigation of liquefaction and associated ground deformations by stone columns. Engineering Geology 72 (3): 275-291.
Barratt, B. J., and Day, P. W. 2016. Geotechnical design using SANS 10160: A comparison with current practice. In Proceedings of the First Southern African Geotechnical Conference (p. 121). May 17, 2016 by CRC Press, ISBN 9781138029712 - CAT\# K29785.

Bolton Seed, H., K. Tokimatsu, L. Harder, and R.M. Chung. 1985. Influence of SPT procedures in soil liquefaction resistance evaluations. Journal of Geotechnical Engineering 111 (12): 1425-1445.

Cetin, K.O., and R.B. Seed. 2004. Nonlinear shear mass participation factor ( $r$ d) for cyclic shear stress ratio evaluation. Soil Dynamics and Earthquake Engineering 24 (2): 103-113.

Cetin, K.O., R.B. Seed, A. Der Kiureghian, K. Tokimatsu, L.F. Harder Jr., R.E. Kayen, and R.E. Moss. 2004. Standard penetration test-based probabilistic and deterministic assessment of seismic soil liquefaction potential. Journal of Geotechnical and Geoenvironmental Engineering 130 (12): 1314-1340.

Chameau, J.-L., and G.W. Clough. 1983. Probabilistic pore pressure analysis for seismic loading. ournal of Geotechnical Engineering 109 (4): 507-524.

Choobbasti, A., Naghizaderokni, M., and Naghizaderokni, M. 2015. Reliability analysis of soil liquefaction based on standard penetration: a case study in Babol city. In 2015 International Conference on Sustainable Civil Engineering (ICSCE 2015).

Dawkins, R. 2016. The selfish gene. London: Oxford university press.

Duncan, J.M. 2000. Factors of safety and reliability in geotechnical engineering. Journal of Geotechnical and Geoenvironmental Engineering 126 (4): 307-316.

Farrokhzad, F., A. Choobbasti, and A. Barari. 2012. Liquefaction microzonation of Babol city using artificial neural network. Journal of King Saud UniversityScience 24 (1): 89-100.

Hwang, J.-H., and C.-W. Yang. 2001. Verification of critical cyclic strength curve by Taiwan chi-chi earthquake data. Soil Dynamics and Earthquake Engineering 21 (3): 237-257.

Idriss, I., and R. Boulanger. 2006. Semi-empirical procedures for evaluating liquefaction potential during earthquakes. Soil Dynamics and Earthquake Engineering 26 (2): 115-130.

Ishihara, K. 1993. Liquefaction and flow failure during earthquakes. Geotechnique 43 (3): 351-451.

Iwasaki, T. 1986. Soil liquefaction studies in Japan: State-of-the-art. Soil Dynamics and Earthquake Engineering 5 (1): 2-68.

Iwasaki, T., T. Arakawa, and K.-I. Tokida. 1984. Simplified procedures for assessing soil liquefaction during earthquakes. International Journal of Soil Dynamics and Earthquake Engineering 3 (1): 49-58. 
Iwasaki, T., Tokida, K., and Tatsuoka, F. 1981. Soil liquefaction potential evaluation with use of the simplified procedure. International Conferences on Recent Advances in Geotechnical Earthquake Engineering and Soil Dynamics. Janalizadechoobbasti, A., M. Naghizaderokni, and A. Talebi. 2016. A study of the effect of soil improvement based on the numerical site response analysis of natural ground in Babol City. Open Journal of Civil Engineering 6 (02): 163.

Jha, S.K., and K. Suzuki. 2009. Reliability analysis of soil liquefaction based on standard penetration test. Computers and Geotechnics 36 (4): 589-596.

Journel, A. 1986. Constrained interpolation and qualitative information-The soft kriging approach. Mathematical Geology 18 (3): 269-286.

Juang, C.H., C.J. Chen, T. Jiang, and R.D. Andrus. 2000. Risk-based liquefaction potential evaluation using standard penetration tests. Canadian Geotechnical Journal 37 (6): 1195-1208.

Kutanaei, S.S., and A.J. Choobbasti. 2015. Prediction of combined effects of fibers and cement on the mechanical properties of sand using particle swarm optimization algorithm. Journal of Adhesion Science and Technology 29 (6): 487-501.

Liao, S.S., and R.V. Whitman. 1986. Overburden correction factors for SPT in sand. Journal of Geotechnical Engineering 112 (3): 373-377.

McCully, C., and C. Bleobaum. 1996. A genetic tool for optimal design sequencing in complex engineering system. Struct. Optim. J 12: 186-201.

No, S. 2005. 2800-05. Iranian code of practice for seismic resistant design of buildings. Tehran: Third Revision, Building and Housing Research Center

Rokni, M.N., M. Hassanlo, and M. Ramzani. 2017. A developed procedure for predicting the risk of liquefaction: A case study of Rasht City. International Journal 12 (29): 59-65.

Seed, H. B., and Idriss, I. M. 1971. Simplified procedure for evaluating soil liquefaction potential. Journal of Soil Mechanics \& Foundations Div, ASCE 97, SM9, 1249-1273.

Sert, S., Z. Luo, J. Xiao, W. Gong, and C.H. Juang. 2016. Probabilistic analysis of responses of cantilever wall-supported excavations in sands considering vertical spatial variability. Computers and Geotechnics 75: 182-191.

Yaghmaei-Sabegh, S., and H. Mohammad-Alizadeh. 2012. Improvement of Iranian seismic design code considering the near-fault effects. International Journal of Engineering-Transactions C: Aspects 25 (2): 147.

Youd, T., I. Idriss, R.D. Andrus, I. Arango, G. Castro, J.T. Christian, et al. 2001. Liquefaction resistance of soils: Summary report from the 1996 NCEER and 1998 NCEER/NSF workshops on evaluation of liquefaction resistance of soils. Journal of Geotechnical and Geoenvironmental Engineering 127 (10): 817-833.

Zhang, W., and A.T. Goh. 2016. Evaluating seismic liquefaction potential using multivariate adaptive regression splines and logistic regression. Geomechanics and Engineering 10 (3): 269-284

Zhang, W., A.T. Goh, Y. Zhang, Y. Chen, and Y. Xiao. 2015. Assessment of soil liquefaction based on capacity energy concept and multivariate adaptive regression splines. Engineering Geology 188: 29-37.

\section{Submit your manuscript to a SpringerOpen ${ }^{\circ}$ journal and benefit from:}

- Convenient online submission

- Rigorous peer review

- Open access: articles freely available online

- High visibility within the field

- Retaining the copyright to your article

Submit your next manuscript at $\boldsymbol{\nabla}$ springeropen.com 